Article received on April $6^{\text {th }} 2016$

Article accepted on June $30^{\text {th }} 2016$

UDC: 78:004

\author{
Ivana Ančić* \\ University of Arts in Belgrade \\ Interdisciplinary Studies \\ Doctoral studies in Theory of Art and Media
}

\title{
SOUND FROM THE CLOUD: METAMORPHOSES OF TECHNICAL AND ARTISTIC PARADIGMS IN THE SOCIAL RECEPTION OF SOUND AND MUSIC
}

\begin{abstract}
In this paper on the example of the cloud I intend to research and analyze the changes of artistic paradigms and practices in music that occurred due to the technological development, digitalization process and implementation of new media. With the rapid growth of technology and its immersion in digital screen culture, reality has become virtual and augmented, moving our perception to a different, new perspective - the cloud perspective. Sound from the cloud represents a new category of the production, distribution, consumption and perception of sound, the new sound/cloud discourse. This is the case of sound coming from virtual space, but due to the development of new devices and mobile phones it does not require the connection of the consumer to the computer, but is already connected through the mobile and omnipresent web. The purpose of this paper is to focus on the impacts achieved in the field of music by the system of recording and sound reproduction and digital technology, as well as to analyze some theoretical issues provoked by these changes. The special focus of the research is an innovative artistic practice which has developed parallel with technological development, digital consumption and listening habits, contrary to artistic experience. This paper should confirm that the rapid and intensive development of technology and devices is developing a new space and intimate connection between authors, prosumers and consumers. The research should also confirm the hypothesis that the cloud is an entity, an autonomous system, a live organism in constant change, dependent and in a constant process of interaction.
\end{abstract}

Key words: digital technology, sound/music, Internet, cloud computing, cloud, apparatus

\footnotetext{
* Author contact information: ancic.ivana@gmail.com
} 


\section{Introduction}

The processes of the production and consumption of music have changed and have become pronouncedly blurry and fluid. While music has always relied on the technology of production, distribution and consumption, music in a cloud is a technologized vision of music demanding numerous preconditions for reproduction. New technologies have brought new ways of interaction with music and a new platform in the form of the cloud in which this interaction is happening through the Internet. Paul Jaeger defines cloud computing as the "resulting computing model where machines in large data bases can by dynamically provided, configured and reconfigured to deliver services in an adjustable way for a wide scope of needs - from scientific research to video and e-mail sharing". ${ }^{1}$ This is a particular music recording whereby music networked between providers and technologies is seen as a cultural commodity. However, the aesthetical criterion and the artistic value of cloud contents are questionable and doubtful. 'The dark side of cloud programming' raises the question of trust, control, access, server location, data security and potential server failure. These metamorphoses influence artistic practice, production and distribution systems and auditory control. Technological development and the expertise of IT experts have found a new way to satisfy the broad consumer masses of the most diverse types of music. The transformation that occurred due to the development and application of digital technology has a global scale and it raises the question: "How far are we ready to go and digitalize our life?"

The hypothesis from which I start is that the cloud is an entity, a live organism in constant change. The cloud acts as a medium for personal and social transformation. The purpose of this hypothesis is to question the concept of the agency of actors, human and non-human, their mutual relationships, causalities and responsibilities through constant cooperation and the co-creation of sociological and material practices in everyday life. The process of transformation, the implementation of new technologies and new sound practices shall be addressed and followed through the relationship of human and non-human (technological, instrumental, mechanical) actors and the understanding of the cloud from the aspect of Agamben's apparatus.

Musical and social platforms, communities and networks, and culture originating from the context of such networking and exchange of MP3 files in cyberspace, have commenced a new musical discourse in which a man/creator

\footnotetext{
1 Paul T. Jaeger, Jimmy Lin, Justin M. Grimes, and Shannon N. Simmons, "Where is the cloud? Geography, economics, environment, and jurisdiction in cloud computing", in: First Monday, Vol. 14, No. 5, 2009, 277, http:/firstmonday.org/htbin/cgiwrap/bin/ojs/index.php/ $\mathrm{fm} /$ article/view/2456/2171, ac. January 8, 2016.
} 
(whether amateur or professional) increasingly expresses himself through technology and through it he consumes musical and other types of contents.

The Sound Cloud, You Tube, iTunes, Spotify, Amazon, Google Play as some of the most widespread creations and inventions in the $21^{\text {st }}$ century have become the synonym for listening, exchange, sharing, creating and arranging music applications, platforms, social and music networks, educational workshops, in a word, a virtual space assembling musicians (amateurs and professionals), music admirers, music producers, record houses, and scientists from different fields. However, these cultural contexts have become more complex with the appearance of new ways of performing, producing and listening to music. As digital contexts have rapidly expanded throughout the world, categories of producers and consumers are intertwined, cave into each other, and unite forming a new category of "prosumers".

\section{The influence of digital technology on the production, distribution and reception of music}

When the phonograph was invented the purpose of each recording was to simulate a live performance, to come as close as possible to reality. The repetition of recorded sound influenced the expectations of listeners worldwide. Over the decades, these expectations have changed for many listeners - perhaps for most - music is now a technologically mediated experience. Concerts, thus, "live according to the recordings". Given that for centuries live music has been the only type of music, it is astonishing how fast this "ideal" model has been replaced. ${ }^{2}$

During the past century, music has been transformed due to requirements for the human performer/composer/producer of the sound to be replaced with mechanical and digital means. While critical, aesthetical and pedagogical discussions of performance still deal with issues of expressivity and individual subjectivity, the automatization of sound creation is deeply determined in modern culture. Music performance is conducted in the context of the highly increasing and sophisticated reproduction technology that during the past century has been commercially promoted as a means of inspiration, craftsmanship and the human touch. "The human touch" is, paradoxically, advertised in reference to technologies designed to replace it. The understanding of a technologically mediated performance takes into account the swift development of technological simulations together with the deeply rooted discourse of mimicry and humanization that follows them.

${ }^{2}$ Cf. Mark Katz, Capturing Sound: How Technology Has Changed Music, Berkeley and Los Angeles, University of California Press, 2010, 58. 
Given that this paper deals with the metamorphosis of artistic/technological practices, in this chapter I shall speak specifically of musicians who use digital technology to simulate sounds of instruments, such as organs, guitars, brass instruments, woodwind instruments and percussion. Namely, although there is a rich selection of a creative and interactive use of digital technology in sound production, the commercial recording of music is dominated by this simulation logic. Jean Baudrillard points to the difference between the real and illusion being lost. The era of simulations begins with abandoning the referential and its artificial resurrection in sign systems. He determines the simulation as the production with the use of models, something unreal without origin or reality, something supernatural. This is no longer an illusion, duplication or parody; this is a musical replacement of something real with its signs. "New" reality is produced starting from miniature cells, matrices and memories, management models; hence it is possible to reproduce countless times. This "new real" is something "supernatural", the product of synthesis achieved by the radiation of combinatorial models.

The music is not created necessarily and exclusively by musicians. With the appearance and development of digital technologies, numerous music platforms and music clouds, the listener/consumer himself is able to become a creator/producer if he has the skills and talent so long as he is open enough, brave and interested in trying something new, something that has been unattainable till now. Consumers can now produce, arrange and rearrange the music they listen to. The division between consumption and production, between the original and the copy has become blurred.

Alvin Toffler designates this process of turning consumers/listeners into producers/creators, as the occurrence and era of the prosumer - a person who is at the same time the user/buyer of music files and the producer/creator of them. Although we do not know the final outcome which comes after music, we know that this metamorphosis engages the audience in a fundamentally different way. Listeners/users/creators become scattered in space and time, decentralized and demanding, working on their own sound tapes and struggling to keep up with the technology that progresses more and more each day. In the end, there is the need for confirmation of the "human touch" as a force which enables the spreading and pseudo reality of technology. The music we hear today is mediated by the choice we make on the mixer and switches. Since the 1990s, in disco clubs and on the rave scene, DJs who mix and sample previously recorded sounds in order to create new music, have been considered artists. Just as the invention of VCR influenced television viewing, CD players, Walkman, MP3 players, iPod influenced the music audience in the same way. MP3 devices represent the end of the predetermined song lists on the albums such as we have known until now. 
Each user himself increasingly becomes the DJ, creating the sound space and experience. The culture of file sharing has originated from the shadow of underground computer know-how and it has been placed in the mainstream of global music distribution. Walter Benjamin believed that in the "times of mechanical reproduction a uniqueness of aura tends to be understood as the most important quality of a work of art". ${ }^{3}$ He hoped that new technologies would lead to the democratization of culture goods. But, as he doubted, the desire for originality is difficult to negate and the magical aura has not disappeared with the spreading of what was considered earlier as high culture. The aura has not even been demystified, but it is widespread and pervasive in other culture forms. ${ }^{4}$ Now the mark "authentic" is transferred from the original to the copy. For example, new technological procedures of music production from the late 1970s imply that the original music was created in a studio and not on stage: the authentic is what is recorded now. Slavoj Žižek sees that in artificial intelligence, technology and performance continue to imitate each other and they tend to represent this wish in continuous imitation of the human measure. ${ }^{5}$ Recordings simulate live recordings which in return simulate the live performance. Musicians in concerts are encouraged to imitate their own live performances. The live concert can seem like a "pale reflection of the recording" because the live ear cannot be omnipresent. Technological reproduction creates new expectations in the audience. Thus, musicians in live performances imitate recordings, whereby a new standard is created for the live performance. Changes in musical expectations and perception create new performance conventions in which live music and technologically mediated music imitate each other, whereby each tries to impose a stronger "presence" in the audience. The attempt to create a sense of omnipresence is the legacy of modern audio-visual recordings and transfer technology. This project is also expanded and reversed. With music circling the Internet a listener can be anywhere, he can be a part of the music machine if he figures out how to pay the ticket: "Thus, the new medium does not only shape our sensory consciousness, but this transformed consciousness becomes the one which observes". 6

${ }^{3}$ Walter Benjamin, "The Work of Art in the Age of mechanical Reproduction", in: Hannah Arendt (Ed.) Illuminations, New York, Schocken Books, 1969, 4.

${ }^{4}$ Cf. Sarah Thornton, Club Cultures: Music, Media and Subculture Capital, Cambridge, Polity Press, 1995.

5 Cf. Slavoj Žižek, "From Virtual Reality to the Virtualization of Reality", in: David Trend (Ed.), Reading Digital Culture, Malden, Mass and Oxford, Blacwell Publishers, 2001, 21-22. 6 Jon Frederickson, "Technology and Music Performance in the Age of Mechanical Reproduction", in: International Review of the Aesthetics and Sociology of Music, 1989, 20(02), 199. 
With the appearance of CD technology, the permanence and invariability of reproduction are stable, but many audiophiles, true to the vinyl record, still claim that a digital sound recording "deprives of the natural" the spectrum of tones of the vinyl record in a similar way as it is claimed today that MP3 compression technology worsens the quality of reproduction in such a way that the mid-tones "suffer". Of course, many of the entropic effects of reproduction are incorporated in the catalog of studio effects, as musicians themselves started using them as quoted or ready-made elements in music creation. With computer music, the sound becomes the result of composing, and not an existing object, which means that the traditional dualism between structures of sound materials (microstructures) and music structures (macrostructures) has been cancelled, and that the emphasis is shifted to what is called algorithm composing and timbre design (a popular example of this new practice is new electronics). In the development of art and the creation of new art branches, technological innovations can represent only an impulse, and not a solution. Even the highest quality technological solution does not have to have as a consequence such an artistic reaction which will lead to qualitatively new and better works.

\section{Cloud computing}

Cloud computing dates back to the 1960s when computer visionaries such as J.C.R. Licklider and John McCarthy described the vast network of connected computers which enabled access to all types of programs and services from any type of devices. ${ }^{7}$ Some of the first constructors of the Internet, Vinf Cerf and Bob Taylor used clouds and other "ameba" structures to represent the Internet because the cloud seemed to be a suitable metaphor for mapping the diffuse nature of the Internet. ${ }^{8}$ In many ways, cloud computing is actually a return to previous models of computing where "users from computers of very little power accessed information stored in the main computer". ${ }^{9}$ This principle now seems new because in the last three decades we have relied on the model of a personalized

7 Cf. Nicholas Carr, Cloud computing, circa 1965, 2009, (28 November), http://www.roughtype.com/archives/2009/11/cloud_computing_1.php, ac. January 12, 2016; Arif Mohamed, "A history of cloud computing", in: Computer Weekly, 2009, (27 March), http://www.computerweekly.com/Articles/2009/06/10/235429/A-history-of-cloud-computing.htm, ac. January $12,2016$.

${ }^{8}$ Cf. Jessie H. Scanlon and Brad Wieners, "The Internet cloud", in: Industry Standard (9 July), 1999, http://www.thestandard.com/, ac. December 17, 2015.

9 John Horrigan, "Use of cloud computing applications and services", in: Pew Internet \& American Life Project (12 September), 2008, 5, http://www.pewinternet.org/Reports/2008/ Use-of-Cloud-Computing-Applications-and-Services.aspx, ac. December 10, 2015 
computer where the processor power and applications are stored on the desktop of the user computer. ${ }^{10}$

If there is something "new" in reference to the current edition in cloud computing, then it is energy and the means which companies invest to build the data storage, technical aspects and hardware/software platforms used for cloud access. From the point of view of businesses, companies such as Google, Microsoft and Amazon rent a space for the storage and/or power of the computer processor to other businesses with weaker technological infrastructure. ${ }^{11}$ From the point of view of users, cloud computing is more than ever present and included in our everyday computer practice. The basic idea of cloud computing lies in the fact that in the future information technologies will be treated as a service and they will be contracted as a service for telephone, electric energy or gas. The collection of music inside the boundaries of music online service providers raises the question of collection status. ${ }^{12}$ Keeping a music collection in a cloud means that we never know where those files are placed, and we never completely control their management and organization. The metaphor of the cloud blurs the fact that this transition is a much more simple transition from the treatment of music as a cultural commodity to the treatment of music as a service.

\section{The term Internet and global exchange of MP3 files}

The Internet, more than any other technology of new media, at its best demonstrates the changes and novelties in the field of music, modern culture and society. As a new tool for communication, which indeed enabled a new field of discourse, it initiated an entire new vocabulary and specialized glossary, ways of creation and consumption of languages and signs, and simultaneously practices and virtual objects which do not have similar representations in any other media or in real life (online file sharing, downloading, streaming, hypertext link). This is why this new media is par excellence.

We can "personify" the phenomenon of the "disobedient" online identity (illusive, in constant movement and in search of itself) as a modern Odyssey (aware of his choice of self exile) or it can be recognized by a rhizome which, as Gilles Deleuze and Felix Guattari write, is a "discentered, non-hierarchical, un-

${ }^{10}$ Cf. Ibid., Brian Hayes, "Cloud computing", in: Communications of the $A C M$, volume 51, number 7,2008, 9-11, http://dx.doi.org/10.1145/1364782.1364786, ac. December 10, 2015.

${ }^{11}$ Cf. John Horrigan, "Use of cloud computing applications and services", in: Pew Internet \& American Life Project (12 September), 2008, 5, http://www.pewinternet.org/Reports/2008/ Use-of-Cloud-Computing-Applications-and-Services.aspx, ac. December 10, 2015.

12 Cf. Patrick Burkart, Music and CyberLiberties, Middletown, Conn, Wesleyan University Press, 2010, 128. 
marked system without generality and without organization of memory or central automatization, determined only by the circulation of the state". Although the Internet creates new places for "meetings" and makes the world "smaller and closer", it also gives the opportunity for escapism which is characterized in alienation and finally, human absence from the integral environment. It turns out that the Internet is a form of non-communication. This is sort of paradox of the "screen culture", at the same time completely alienated and individualized up to a single entity in front of the screen, but also a multitude of (equally) isolated entities connected to a multiplicity of communication and representative networks. Our experience of the Internet is mediated by a screen which appears as a curtain between two worlds. The psychoanalytical metaphor determines a phantasm as a screen which separates a subject from reality, i.e. the screen appears as the very form of misunderstanding, impossible understanding.

In the context of digital society and the Internet technology the analogy is clear: the Internet is a "space/territory" occupied by depersonalized authorities, who introduce surveillance and control through the profiling of online users ${ }^{13}$, establish monopoly over the speed of the information flow, favor the popular social networks as the type of virtual roadways and check points and similar ${ }^{14}$. The Internet has rapidly become the subject of numerous regulations and restrictions, software devices and communication protocols, whereby the world is slowly being introduced into a state of total control and surveillance. Alex Galloway builds on the views of Foucault and Deleuze and he characterizes the digital age with protocols, invisible but omnipresent codes, which simultaneously enable and limit what can or cannot be done in the given online system. ${ }^{15}$

It is a fact that the entire world is determined by information which is used in different ways: possessing information is of vital importance, and fabrication and manipulation with it is the main strategy in the aspiration for global domination. Data bases, information and other digital resources have become useful means to the power centers of the Western countries for the implementa-

${ }^{13}$ The important term here is "cookies" - small programs which serve as identification of IP address, recording of each transaction and for precise emission of marketing messages. Many are voluntarily accepted by us while logging into inbox and often we are not aware of their infiltration since they are hidden behind user services.

14 There are numerous intrigues on misuse of data collected in the base of popular Facebook social network. The harshest critique at the expense of this social network comes from Richard Stallman, the founder of the Free Software Foundation. He calls the Facebook a machine for digital surveillance of people. More on: http://www.fsf.org/facebook, ac. September 28, 2015, at 13:14.

15 Cf. Alexander R. Galloway, Protocol: how control exists after decentralization, London, The MIT Press, 2004, 243-244. 
tion of different aims, and the research of this revolution and phenomenon, also includes encroachment on the conflicts between recording houses, industries for sound recording and Intellectual Property Laws. Although piracy represents a big danger for recording houses and artists, the wide exchange of files through the Internet represents a public good and accordingly to the publishing industry, and Intellectual Property Law should adjust to this new listening and distribution model.

The MP3 file did not have an immediate impact on modern music life. In the beginning of the 1990s, a few people was aware of the characteristics and potential of the format, and even fewer had access to MP3 files. Only with the growth and development of the P2P (peer to peer) network later during the decade, most notably with the appearance of Napster, MP3 has achieved its global influence. The P2P network is radically different from the traditional client-server model in which information comes and flows from the central source (server, computer or group of computers which store and distribute data) to users (clients who ask for information from the server). P2P, in contrast, denotes a non-centralized network in which each computer has direct access to certain marked files stored in any other computer. Each network member is a "peer", and data circulation among "peers" is known as file sharing. On the Internet, P2P networks connect millions of users who can share and exchange data almost instantaneously. Programs for a distributed file exchange have rapidly enter the focus of public interest as the most advanced concept of the application of open Internet architecture in the second half of the 1990s.

The last two decades testify, though not unprecedentedly, to the large turnabout for individuals and institutions included in the making, marketing, distribution, sale and consumption of popular recorded music. Once an industry worth approximately 45 million dollars in 1997, recorded music has cut its value in half (IFPI - International Federation of the Phonographic Industry). As a reaction, the major record labels - Sony, Universal, Warner, EMI - and industrial associations which represent them - RIAA, IFPI and others are conducting a fierce legal, educational and public campaign against what they see as the culprit in the crisis - piracy through the Internet and networks for file sharing. The reality is, however, much more complicated and research points to the weak connection between file sharing and lost profit. Moreover, the increase in profit in digital sales, tours and other income sources open a new dimension of growth. ${ }^{16}$

16 Cf. Todd Martens, "Overall Music Sales Hit an All-Time High in 2009", in: Los Angeles Times (12 January), 2010, http://latimesblogs.latimes.com/music_blog/2010/01/overall-music-purchases-hit-an-alltime-high-in 2009.html, ac. January 13, 2016. 
The turning of music into digital files meant at the same time the turning of music into software. Music is today part of the network technology, integrated in the multimedia computer experience. Mobile telephones are sold with music, as well as web sites, video games and new cars. CDs are routinely given with newspapers and magazines as promotion. ${ }^{17}$ Social networks, search engines and other similar technologies use music as an outline of their services. Instead of the commodity character it had earlier, music is now integrated in a multitude of different services so it is difficult to speak of music as a specific and original experience. It seems that music is therefore omnipresent: simultaneously everywhere and nowhere. ${ }^{18}$

This abstract omnipresence finds its match in the increase of cloud based services. Cloud services promise enormous space for the storage of user files, playlists, preferences and information, as well as access to remote data, regardless of the type of device or location. As we relied on our own gadgets for our computer needs, now we buy parts of the daily activities in the cloud. ${ }^{19}$ Cloud computing represents the replacement of the use of our own machines for control of our data in contrast to the confidence we place in the network to store them instead of us. ${ }^{20}$ This is a commercialization of services, such as data storage, information processing and computer power.

\section{Understanding cloud from the perspective of Agamben's apparatus}

In order to understand how the concept and technological apparatus and its relevant practice of the cloud function in modern media ecology, it is necessary to combine chosen field research (interactive observation) with discourse analysis and dispositive analysis. In this sense, it is necessary to understand and study what the apparatus really is.

Agamben's starting hypothesis is that the term dispositive or apparatus in the English language marks a decisive technical term within the Michael Fou-

17 Cf. Will Straw, "In memoriam: The music CD and its ends", in: Design and Culture, Vol. 1, No. 1, 2009, 79-92, http://dx.doi.org/10.2752/175470709787375751, ac. January 13, 2016.

18 Cf. Anahid Kassabian, "Ubiquitous listening and networked subjectivity", in: Echo: $A$ Music-Centered Journal, Vol. 3, No. 2, 2001, 16, http://www.echo.ucla.edu/volume3-issue2/ kassabian/Kassabian3.html, ac. 10 December, 2015.

${ }^{19}$ Cf. John Horrigan, "Use of cloud computing applications and services", in: Pew Internet \& American Life Project (12 September) 2008, 5, http://www.pewinternet.org/Reports/2008/ Use-of-Cloud-Computing-Applications-and-Services.aspx, ac. December 10, 2015.

${ }^{20} \mathrm{Cf}$. Brian Hayes, "Cloud computing", in: Communications of the $A C M$, Vol. 51, No. 7, 2008, 9-11, http://dx.doi.org/10.1145/1364782.1364786, ac. December 10, 2015. 
cault strategy of thought. He has often used this term, especially from the mid1970s when he started to take an interest in human rule. Although he never offered a complete definition, in his interview from 1977 he offered the closest definition:

What I am trying to single out with this term is, first and foremost, a thoroughly heterogeneous set consisting of discourses, institutions, architectural forms, regulatory decisions, laws, administrative measures, scientific statements, philosophical, moral and philanthropic propositions - in short, the said as much as the unsaid. The apparatus itself is the network that can be established between these elements... 21

...by the term apparatus I mean a kind of formation, that at a given historical moment has as its major functions the response to an emergency. The apparatus, hence, has a dominant strategic function...

...The apparatus is precisely this: a set of strategies of the relations of forces supporting, and supported by certain types of knowledge. ${ }^{22}$

As an amendment and summary, Agamben points out three major points of the apparatus definition:

- It is a heterogeneous set that includes virtually anything, linguistic and nonlinguistic, under the same heading: discourses, institutions, buildings, laws, police measures, philosophical propositions and so on. The apparatus itself is the network established between these elements.

- The apparatus always has a concrete strategic function and it is always located in a power relation.

- As such it appears at the intersection of power relations of knowledge. We can trace a genealogy of this term, first in the work of Foucault, and then in a broader historical context.

Agamben's definition of the term apparatus, hence, can be essentially, formally and functionally translated and referred to as the term cloud which also consists of formations and legal regulations and it functions within the network. In the heart of progress of cloud computing lays a strong metaphor which describes a special vision of computing. Like large, white, puffy clouds in the sky lit by the sun on a summer day, the Internet clouds are omnipresent and extremely dispersive. The Cloud is an idealized display of what we expect from our information: always "there", wherever we are. Primarily, clouds evoke positive

${ }^{21}$ Giorgio Agamben, What is An Apparatus?, Stanford, Stanford University Press, 2009, 2-4.

22 Ibid. 
images. They reflect the "vision of a paradise on Earth", so the Internet as a cloud is some kind of "holy condensation of bites". ${ }^{23}$

However, the metaphor of the cloud simultaneously also covers and uncovers its properties. Data in the cloud reflect very few data on how they were formed and what they contain. Given that cloud can be anywhere and everywhere as long we have access to a computer, it is easy to foresee server farms, energy storage or geographical, economic and political conditions which form the very existence of the cloud. ${ }^{24}$ Behind the idea on the essential and distributed network of connections and traffic lie the cold and cruel materialistic server storages, generators and other control devices: "In reality, the cloud are huge buildings full of computers and diesel generators. There is nothing white and puffy about it". ${ }^{25}$ Except legal issues, the cloud examines the aesthetical problems of music experience.

The term apparatus within Foucault's strategy takes the place of one of the terms which he critically defines as universals. Foucault has always declined a general categorization and mental constructs which he called universals, such as the State, sovereignty, law and power. Apparatuses are, actually, what took the place of the universals in Foucault strategy: not simply this or that police measure, this or that technology power, not even a generality obtained by abstracting them. Instead, as he says in his interview from 1977, the apparatus is a "network" which can be established between these elements. ${ }^{26}$

If we try to find and test the definition of the apparatus which can be found in an ordinary French dictionary, we shall see that there are three meanings of this term:

1. A strictly judicial meaning: "The Apparatus is part of the assessment which contains the decision separated from the opinion". That is the part of the sentence which decides, or the decisive clause of the law.

2. A technological meaning: "The way in which parts of a machine or mechanism, and additionally, the mechanism itself, are arranged."

3. A military use: "The set of devices arranged in accordance with the plan".

${ }^{23}$ Cf. Jessie H. Scanlon and Brad Wieners, "The Internet cloud", in: Industry Standard, (9 July), 1999, http://www.thestandard.com/, ac. December 17, 2015.

${ }^{24}$ Cf. Paul T. Jaeger, Jimmy Lin, Justin M. Grimes, and Shannon N. Simmons, "Where is the cloud? Geography, economics, environment, and jurisdiction in cloud computing", in First Monday, Vol. 14, No. 5, 2009, 277, http:/firstmonday.org/htbin/cgiwrap/bin/ojs/index.php/ fm/article/view/2456/2171, ac. January 8, 2016.

25 Ibid.

${ }^{26}$ Michel Foucault, Power/Knowledge: Selected Interviews and Other Writings, 1972-1977, C. Gordon (Ed.), New York, Pantheon Books, 1980, 194-96. 
To a certain extent, all three definitions are present in Foucault. However, dictionaries, especially those which lack a historical and etymological character, separate and divide this term into a multitude of meanings. Such fragmentation generally responds to the historical development and articulation of a unique original meaning that we cannot lose sight of. What is the original meaning of the term apparatus? The term definitely refers to, in its usual Foucault use, a set of practices and mechanisms (linguistic and non-linguistic, legal, technical and military) in which the purpose is to face an urgent need and to obtain an effect which is more or less immediate. The question is, however, about the strategy of practices or thoughts and the historical context from which this modern term dates.

\section{Conclusion}

The rapid and intense technological development, innovation of devices (mobile phones, computers), the new types of services and distribution of music, social networks and musical platforms (You Tube, Facebook, Twitter, Sound Cloud, and My Space), downloading and file sharing practices create new space and an intimate relationship between the author, prosumers, and consumers. A new model of the interactive/participatory/convergence culture and networked society which develops and supports a user-led content creation, new types of presentation, distribution and consumption of music, as well as a new discourse of sound, have encouraged many arts, media, and culture theoreticians and researchers in the field of education, sociology, economics, and psychology to critically consider the paradigm of sound/music from the cloud and explain this new phenomenon which fundamentally changes our listening habits, business model, and the role of technology in the educational system, and finally, our perception and reception of sound and music. These questions were fundamental for my paper which started from the hypothesis that the cloud is an entity, a live organism in constant change. The cloud acts as a medium for personal and social transformation. The analyses and understanding of this hypothesis were achieved and presented through the prism of different theories of media and new media, the concept of Agamben's apparatus, Jenkins' conceptual analyses of convergence culture, and the actor-network theory. The actor, from the sociological standpoint, is perceived as a human "live" unit which can affect the surroundings with its will, consciousness, and ability. However, the unit is not meant to be self-sufficient and isolated from the society, so its identity (e.g. avatar, profile, web page, etc.) is carefully built up, transformed, and sustained within the online, virtual environment. The network of actors/identities/entities always existed in the Arts, but before the appearance and development of a new 
technology, the Internet, and networks, these actors were mostly human (performers, musicians, artists). The situation changed drastically when these actors were replaced or combined with non-human actors (radio, TV) and this was the beginning of a much more complex way of interaction between many agents, actors, and media. In that sense, understanding the term cloud as an entity/live organism actually represents the positioning and determination of the artist/listener and artistic/listening practices within the society and a new social construct of culture in the technologically and media mediated environment. The cloud exists and functions within the network and because of the network. That is, at the same time, its biggest shortcoming and its biggest advantage. Because of the characteristics of the network, the Sound Cloud for example has a slogan "Hear the World's Sounds". This is a very interesting slogan, bearing in mind that electric energy is not available for everyone, not to mention the Internet. The purpose and goal of networking is flow as a basic feature of creative development, connecting, and interaction. The network itself is not an entity, but rather the concept - a tool which helps us to describe, hear, and see things, not the things we are describing, themselves. In other words, the network is a non-material space which enables material, units, and identities in the process of shaping and transformation in the virtual world, where music, creation, information, and complete content of the "networked self" become available, exposed, and a constituent part of the cloud.

The essence of interaction can be seen in their fluidity, flexibility, readiness, and openness for collaboration, exchange and sharing of the content and materials. This is also the main quality of the actor, both human - the need for commenting, exchange, self-improvement and self-realization, and non-human - e.g. the technical preconditions for file sharing, radio broadcasting or live streaming. With that said, we can conclude that the cloud operates through the principle of the entity/live organism because of the complex nature of the human and non-human actors, interactions, network phenomena, and many other technical preconditions. We can also say that due to its ramification and decentration, the cloud functions according to the principle of the "nerve system" or the "blood circulation system" of a living organism which through this metaphorical comparison touches and shows the essence of my hypothesis. The existence of the cloud means that the need for this model of services for the placement of music was recognized in a certain moment. However, I believe that our society is still adjusting to the technological degree, speed, development, and this type of music consumption. Man's need is to create either in a real or virtual world. If, on the one side, we see technology as the force which forms the society, and it forms it today in a way that an ever smaller number of people can be real people, and on the other side we admire musical skills which come from gestures 
we learned through interaction with instruments, people, space and sound by listening to music, it seems that auditory culture and technology shall take the educational, social, aesthetical and many other aspects of the impact to the society. Finding the balance between the importance, sense, and the need for technological usage will be the crucial moment for many people.

Translated by the author

\section{References}

Agamben, Giorgio, What is An Apparatus?, Stanford, Stanford University Press, 2009, 2-4.

Benjamin, Walter, "The Work of Art in the Age of mechanical Reproduction", in: Hannah Arendt (Ed.), Illuminations, New York, Schocken Books, 1969.

Bloustien, Peters and Susan Luckman (Eds.), Sonic Synergies: Music, Technology, Community, Identity, Hampshire, Ashgate, 2008.

Burkart, Patrick, Music and Cyber Liberties, Middletown, Conn, Wesleyan University Press, 2010, 128.

Carr, Nicholas, Cloud computing, circa 1965, 28 November 2009, http://www.roughtype.com/ archives/2009/11/cloud_computing_1.php, ac. 12 January, 2016.

Foucault, Michel, Power/Knowledge: Selected Interviews and Other Writings, 1972-1977. C. Gordon (Ed.), New York, Pantheon Books, 1980, 194-196.

Frederickson, Jon, "Technology and Music Performance in the Age of Mechanical Reproduction", in: International Review of the Aesthetics and Sociology of Music, 1989, 20(2), 199.

Galloway, Alexander R., Protocol: how control exists after decentralization, London, The MIT Press, 2004, 243-244.

Hayes, Brian, "Cloud computing", in: Communications of the ACM, Vol. 51, No. 7, 2009, 9-11, http://dx.doi.org/10.1145/1364782.1364786, ac. January 23, 2016.

Horrigan, John, "Use of cloud computing applications and services", in: Pew Internet \& American Life Project, 12 September 2008, 5, http://www.pewinternet.org/Reports/2008/ Use-of-Cloud-Computing-Applications-and-Services.aspx, ac. December 10, 2015.

Hosokawa, Shuhei, The Aesthetics of Recorded Sound, Tokyo, Keiso Shobo, 1990.

International Federation of the Phonographic Industry (IFPI), 2011, IFPI digital music report 2011: Music at the touch of a button. London: International Federation of the Phonographic Industry, http://www.ifpi.org/content/library/DMR2011.pdf, ac. on January 8, 2015.

Jaeger, Lin, and Justin M. Grimes, "Cloud computing and information policy: Computing in a policy cloud", in: Journal of Information Technology \& Politics, Vol. 5, No. 3, 2008, 269-283, http://dx.doi.org/10.1080/19331680802425479, ac. January 10, 2016.

Jaeger, Lin, Grimes, and Shannon N. Simmons, "Where is the cloud? Geography, economics, environment, and jurisdiction in cloud computing", in: First Monday, Vol. 14, No. 5, 2009, 277, http://firstmonday.org/htbin/cgiwrap/bin/ojs/index.php/fm/article/ view/2456/2171, ac. January 8, 2016. 
Johnson, Bobbie, "Cloud computing is a trap, warns GNU Founder Richard Stallman", in: Guardian, 29 September 2008, http://www.guardian.co.uk/technology/2008/sep/29/ cloud.computing.richard.stallman, ac. December 12, 2015.

Kassabian, Anahid, "Ubiquitous listening and networked subjectivity", in: Echo: A MusicCentered Journal, volume 3 number 2, 2001, 16, http://www.echo.ucla.edu/volume3issue2/kassabian/Kassabian3.html, ac. December 15, 2015.

Katz, Mark, Capturing Sound: How Technology Has Changed Music, Berkeley and Los Angeles, University of California Press, 2006.

Manovich, Lev, The Language of New Media, London, The MIT Press, 2001.

Martens, Todd, "Overall Music Sales Hit an All-Time High in 2009", in: Los Angeles Times, 12 January 2010, http://atimesblogs.latimes.com/music_blog/2010/01/overall-musicpurchases-hit-an-alltime-high-in 2009.html, ac. January 12, 2016.

Mohamed, Arif, “A history of cloud computing”, in: Computer Weekly, 27 March 2009, http:// www.computerweekly.com/Articles/2009/06/10/235429/A-history-of-cloud-com puting.htm, ac. December 20, 2015.

Радовановић, Владан, Музика и електроакустичка музика, Сремски Карловци/Нови Сад, Издавачка књижарница Зорана Стојановића, 2010.

Scanlon, Jessie H. and Wieners, Brad, "The Internet cloud", in: Industry Standard, 9 July 1999, http://www.thestandard.com/, ac. December 17, 2015.

Straw, Will, "In memoriam: The music CD and its ends", in: Design and Culture, Vol. 1, No. 1, 2009, 79-92, http://dx.doi.org/10.2752/175470709787375751, ac. December 27, 2015.

Thornton, Sarah, Club Cultures:Music, Media and Subcultural Capital, Cambridge, Polity Press, 1995.

Žižek, Slavoj, "From Virtual Reality to the Virtualization of Reality", in: David Trend (Ed.), Reading Digital Culture, Malden, Mass and Oxford, Blacwell Publishers, 2001. 